\title{
University Business Incubators: An Institutional Demand Side Perspective on Value Adding Features
}

\author{
Sven Dahms, Suthikorn Kingkaew
}

A B S T R A C T

Objective: The purpose of this article is to investigate differing demands for university business incubator's value adding features. It introduces an institution based perspective to guide the argumentation. A framework has been developed, which is grounded in recent entrepreneurship theory and studies related to business incubator development.

Research Design \& Methods: An exploratory empirical study has been conducted to test the framework using participants from the United Arab Emirates and Thailand. The survey questionnaire was developed and tested before applying to the empirical study.

Findings: The findings indicate variation in demands for incubator features in particular related to infrastructure and networking services. In line with the expectations, no differences have been found for the business support services. We also found that a more general strategy and goals seem to be preferred over a more narrow industry focus.

Implications \& Recommendations: The framework and our empirical findings suggest that university business incubators should take into consideration institutional differences between the countries in order to increase acceptance of the incubator concept, especially in developing countries.

Contribution \& Value Added: The study addresses a research gap, identifying crosscountry differences in the demand of potential entrepreneurs for value adding features provided in University Business Incubators (UBI).

\begin{tabular}{|c|c|}
\hline Article type: & research paper \\
\hline Keywords: & $\begin{array}{l}\text { University Business Incubator; institution; developing countries; } \\
\text { demand side; value adding features }\end{array}$ \\
\hline JEL codes: & $\mathrm{M0}, \mathrm{O} 31$ \\
\hline Received: 1 & Accepted: 6 August 2016 \\
\hline
\end{tabular}

\section{Suggested citation:}

Dahms, S., \& Kingkaew, S. (2016). University Business Incubators: An Institutional Demand Side Perspective on Value Adding Features. Entrepreneurial Business and Economics Review, 4(3), 4156, DOI: http://dx.doi.org/10.15678/EBER.2016.040304 


\section{INTRODUCTION}

The concept of University Business Incubators (UBI) keeps attracting attention from various scholars in wider entrepreneurship literature (Bruneel, Ratinho, Clarysse \& Groen, 2012; Rothaermel, Agung \& Jiang, 2007). Popular key areas are technology diffusion processes, the survival rates of business ventures or various typologies of incubators (Barbero, Casillas, Ramos \& Guitar, 2012; Grimaldi \& Grandi, 2005; Todorovic \& Suntornpitug, 2008).

The importance of incubators for the regional and national economy has been well established over the years in studies that looked for example at Europe (EC, 2002), Taiwan (Tsai, Hsieh, Fang \& Lin, 2009) or US (Mian, 1996). However, the success factors for university and other business incubator models are somewhat more controversial (Barbero et al., 2012; Lee \& Osteryoung, 2004). For example, it has been suggested that variation in success could be caused by the differing reasons for establishing incubators (Chan \& Lau, 2005). University incubators, for instance, have been mostly assessed from a technology diffusion and transfer perspective, where empirical evidence is largely based on incubators located in North America, Europe and to some extend East Asia (Rothaermel et al., 2007). Others investigated the evolution of established incubators over time, arguing that broader economic changes on the regional and national plane alter the requirements for successful incubator models (Bruneel et al., 2012). Another stream of research argues for particular practises, such as tenant screening, which might help to determine success of incubator models in various contexts (Aerts, Matthyssens \& Vandenbempt, 2007). Others indicate that incubators which have been established in recent years around the world seem to follow the North American blue print, with very little consideration towards local needs (Akcomak, 2009; Chan \& Lau, 2005). However, there seems to be very little research on the services or value added features provided by incubators that refer to local requirements. In particular, value adding features that an entrepreneur might find important within an incubator environment is a neglected issue. The demand side of incubators needs attention (Bruneel et al., 2012). That is, the link between university business incubator provisions and the demand from potential entrepreneurs in different countries is under researched.

The current article addresses this gap. The main objective is to identify differences in the demand for value adding features provided in University Business Incubators (UBI) to potential entrepreneurs in different countries. Value adding features mean the provision of tangible (e.g. office space, conference rooms) and intangible services (e.g. networking, business support services) in and by the incubator (Mian, 1996). This research follows Bruneel's et al. (2012) call that incubators must meet tenants' demands in order to become more successful and to fulfil their full potential. The reason for our expectation of differing demands is the growing evidence provided in the adjacent international entrepreneurship literature which suggests that differing institutional settings have a considerable impact on the behaviour of entrepreneurs (Bowen \& De Clercq, 2008; De Clercq, Lim \& Oh, 2011; Estrin, Korosteleva \& Mickiewicz, 2013). Differing institutional settings have been rarely accounted for in demand side literature concerning business incubators. Some notable exceptions in the literature that took local demands by entrepreneurs in incubator context into deliberation are for example a conceptual paper by Zablocki 
(2007). The author suggests that the local environment needs to be taken into consideration and suggests a market analysis to be done in order to understand tenants demands before the incubator is established, but offers little beyond that. Lee and Osteryoung (2004) compare managers' perceptions of critical success factors of UBI's in Korea and US, but only found differences for goals and operational strategies between the participants. Vanderstraeten and Matthyssens (2012) investigate internal and external alignment of incubator strategies, but focus on a European context only. Chan and Lau (2005) provide an overview of tenant's use of incubator services, yet focus on case studies in Hong Kong science parks only, whereas an extensive study conducted by Mian (1996) focuses exclusively on the US.

This study sets out to shed some light on the demands of value adding features provided by UBI's for would be entrepreneurs in different countries. In order to guide the development of our hypothesis, this study will rely on insights from the institutional perspective on entrepreneurship (Baumol, 1990; North, 1990). It thereby attempts to overcome some of the limitations of previous studies in suggesting a coherent framework for the adaptation of the UBI concept to different institutional settings. This study also provides some indicative empirical evidence based on a survey of potential entrepreneurs in the United Arab Emirates (UAE) and Thailand.

This article is structured as follows: the next section provides relevant literature review and general hypothesis are developed. The following section outlines the research design. Next, the analysis and discussion of the results are presented. The last section sums up the conclusions of the article.

\section{LITERATURE REVIEW}

\section{University Business Incubators and Institutions}

Adjacent entrepreneurship literature has emphasised the institutional perspective as one fruitful way to explain various entrepreneurship related phenomena (Bowen \& De Clercq, 2008; De Clercq et al., 2011; Estrin et al., 2013). Baumol (1990) was among the first to point out that the institutional setting in a country determines the entrepreneurial activity and the kind of endeavours undertaken by entrepreneurs. Institutional settings are, for the purpose of this study, defined as consisting of formal (e.g. rules and legislation) and informal (e.g. habits, norms and values) which constrain human behaviour and therefore provide the rules of the game (North, 1990). The institutional setting in a country determines the cost of transaction for social exchanges and hence influences the resource allocation that is paramount for entrepreneurial efforts to develop and sustain (Baumol, 1990; Bowen \& De Clercq, 2008). North (1990) argued that formal and informal institutions are path dependent and change only very slowly through an extended reform process or abruptly through revolution for example. Path dependence can lead to an institutional misfit. That is organisational or institutional forms that work well in one institutional setting, might not work in another institutional setting because it is not aligned to the formal and informal institutional setting in another country. For example, laws for intellectual property rights protection are only useful if enforced and accepted by the social values in a society. We believe that business incubators are one of such organisational forms that might provide valuable economic gains in one setting, but not 
in others. In particular, the institutional constrains on entrepreneurs will determine their set of opportunities available to them (North, 1990). This in turn, is for this study, expected to have an impact on the perceived importance for the demand of value adding features provided by business incubators.

A UBI is one type of business incubator. Various typologies have been proposed in the literature (EC, 2002; Rothaermel et al., 2007). Commonly used categories are public incubators, private incubators, and university incubators (Barbero et al., 2012). The present research focuses on the differing demands for the establishment of UBI's. It is thereby following a general definition of UBI's as suggested in Barbero et al. (2012) and Grimaldi and Grandi (2005). Accordingly a UBI is defined as a university based institution that provides support for young business start-ups through tangible and intangible services in order to support growth and survival of its tenants. Literature indicates that UBI's rely on a mixture of funding from public and private sources. It is thereby emphasised that UBI's do not necessarily have to have a technology focus (Mian, 1996). This is important, because it allows non-technology focussed higher education institutions such as stand-alone business schools, to become active in the incubator market with a particular focus on non-tangible services in addition to technology transfer activities.

UBI's have been chosen for three main reasons. First, it is argued that especially in countries in which incubators are still in their infancy, university based incubators can help start-up businesses to add legitimacy i.e. lower the cost of transaction through trust, based on the location of the tenants under the university tutelage through its location and reputation (Mian, 1996; Chan \& Lau, 2005). This can lower market entry costs for start-ups that generally lack reputation and hence increase the likelihood for survival (Mian, 1996). Second, a reoccurring issue in the entrepreneurship literature across countries is the lack of business and management knowledge in young business start-ups (GEM, 2012). It is argued in this paper that universities, in particular while collaborating with their business schools, are well suited due to their raison d'être in supporting young businesses in that aspect. Thirdly, universities have access to a constantly renewing talent pool, which increases the likelihood of accessing and recruiting new tenants (Barbero et al., 2012; Todorovic \& Suntornpithug, 2008). This might be of particular relevance in developing countries in which the concept of business incubators is still largely unknown (Akcomak, 2009).

\section{Current Context}

Most research on business incubators has been focussed on North America, Europe and developed countries in East Asia (Akcomak, 2009; Rothaermel et al., 2007; Vanderstraeten \& Matthyssens, 2012). Relatively little has been done in the context of emerging regions such as the Middle East or Southeast Asia. This research attempts to narrow this gap by providing indicative empirical evidence collected from potential entrepreneurs in two universities located in the UAE and Thailand.

The UAE is an oil rich nation located on the Arabian Peninsula. Over the last decades, the central and local governments put in increased efforts to shift the economy away from its dependence on crude oil and gas. Various initiatives have been taken to diversify the economy. A particular emphasis has been placed on the development of small and medium sized companies in the country. As part of this policy shift a number of funds have been set up to ease the access to capital for entrepreneurs, various supporting 
organisations have been created such as SME-forums. Among those, a number of public and private business incubators have been set up around the country. Although the concept is still rather alien to the population, increased efforts have been made to provide help and support for entrepreneurs. The country also showed a relatively high perceived competency concerning entrepreneurial activities, but a low level of actual business start-ups (GEM, 2011).

Thailand is a middle income country located in Southeast Asia. The concept of business incubators is still relatively unknown in the country. Different incubator projects have been set up but failed due to various factors such as lack of understanding of the concept, poor funding, or lack of local expertise (Friedrich, Harley \& Langbein, 2012). However, Thailand has a comparatively high rate of entrepreneurial activity among its population compared to other countries in the region (GEM Thailand, 2012). This indicates that the concept of business incubators might be rather useful, if carried out correctly, in both cases.

A study by Scaramuzzi (2002) indicated that there are discrepancies among incubators from different developing countries however the certain characters are required as part of incubation process including facilities, professional services, networking opportunities, access to capital and partnership mechanism.

Building upon a recent study by Bruneel et al. (2012), who suggested a dynamic typology for the incubator industry, this study proposes testable hypothesis along four value adding features of business incubators: goals and strategy, infrastructure, business support services, and networks.

\section{Goal and Strategy of Incubators}

Previous research has indicated that the goals and strategy of incubators are important factors to attract business start-ups (Bruneel et al., 2012). Lalkaka (2003) observed that there are several distinctive characteristics of successful business incubator from different developing countries. Lee and Osteryoung (2004), for example, showed in one of the very few existing comparative studies that goals and strategy were less important for Korean directors of incubators than for US directors. They further argued that this might be caused by the relatively recent introduction of incubators across Korea. Vanderstraeten and Matthyssens (2012) found in their study that the scope of incubators will depend on their choice of providing generalised or specialised services to their tenants. Their findings indicate a dichotomy between interviewed tenants in Belgium. While specialised companies with relatively few market competitors preferred a more general incubator strategy, business start-ups facing broader scope of competition preferred specialised incubators. Explanations for their findings beyond industry have not been provided by the authors. This raises issues concerning generalisability to differing institutional contexts in other countries. Different countries might well nurture differing requirements based on different institutional settings in which UBI's are located. For example, it could be argued that for countries with a long tradition of incubators that a more specialised focus could be preferred in order to take advantage of scale economies. Scale economies derive from further specialised services and a certain incubator image that comes with being located as a tenant in a specialised incubator (Bruneel et al., 2012). Another study by Guerrero, Urbano and Salamzadeh (2015) found that univer- 
sity business incubators in Iran have been transformed under the influence of changing institutional setting in order to better serve local demand.

On the other hand, in countries that are relatively new to the business incubator concept, a more general strategy might be preferred in order to exchange ideas or identify reoccurring issues which affect a number of tenants across a range of industries (Akcomak, 2009). In developing countries, the institutional setting often provides limited support for entrepreneurs (Estrin et al., 2013). Most notably, the protection of intellectual property rights has been emphasised on the formal institutional level (Bowen \& De Clercq, 2008). On the informal institutional level, prevailing uncertainty avoidance has been shown to inhibit entrepreneurial risk taking. In such cases, potential entrepreneurs might prefer a more general incubator strategy in order to learn from a wide range of businesses and role models (De Clercq et al., 2011). Hence, the following hypothesis will be tested.

H1: The importance of general or specialised incubator goals and strategy for potential entrepreneurs varies across countries.

\section{Infrastructure}

As indicated by Bruneel et al. (2012), one of the key features of first generation incubators is the provision of tangible services, i.e. infrastructure. Subsidised office space and other tangible resources such as receptionist services, parking space, or meeting rooms, free incubator tenants from related search and management costs. Shared infrastructure has also been suggested to lead to an increased sharing of information between incubator tenants (Chan \& Lau, 2005). However; the use of shared incubator communication facilities has found only mixed evidence in the literature, dependent on context specific informal institutional variables such as trust or attitude (Chan \& Lau, 2005; Schwartz \& Hornych, 2008; Vanderstraeten \& Matthyssens, 2012). This hints towards differing needs among potential entrepreneurs depending on the formal and informal institutional setting in which they are located.

However, basic infrastructure is provided by the vast majority of physical (as compared to virtual) incubators and has been found to be one of the most important value added features by incubators (Chan \& Lau, 2005). As indicated above this provision reduces the overhead costs such as rents, copy facilities and other office utilities for new businesses. This can be assumed to hold true for new businesses located in expensive metropolitan areas, as well as in more sparsely populated areas due to a potential lack of supply of appropriate facilities. Hence, the following hypothesis will test for differing demands for tangible services.

H2: Infrastructure demand by entrepreneurs will not vary across countries.

\section{Business Support Services}

Business support services include primarily professional services in order to help businesses in their start-up phase such as accounting, in-house bookkeeping, finance, management or marketing (Bruneel et al., 2012; Vanderstraeten \& Matthyssens, 2012). The main reason for providing those services is a general lack of management expertise in young business start-ups (GEM, 2012). Business support services can take the form of subsidised courses offered, or tailored mentoring and coaching services (Lee \& Os- 
teryoung, 2004). More specialised services can be provided on a general level by incubators such as help in recruiting new staff. It has been argued for example in Vanderstraeten and Matthyssens (2012) that many start-ups face the problem of recruiting new staff for their companies. Incubators can provide support in selecting new staff and hence reduce adverse selection risk for new firms. Additionally, in the study above, the authors also found that tenant firms often lack knowledge concerning the development of crucial marketing campaigns or how to engage with the public in general. Business support services on marketing can reduce the costs for developing targeted marketing campaigns and helping to provide guidance concerning public relations of the firms.

Business support services can also help to close the gap between the required knowledge to run a business and the training provided by the educational system prevailing in the country (Bowen \& De Clercq, 2008). We believe that given the lack of human capital in business start-ups, especially in less developed countries (GEM, 2012; Estrin et al., 2013) that there will be no variation in demand for business support services between countries. Hence, the following hypothesis will be tested:

H3: Business support services demand by entrepreneurs will not vary across countries.

\section{Networking Services}

Business start-ups often suffer from a lack of legitimacy in the market place (Chan \& Lau, 2005; Mian, 1996). It has been suggested in the literature that business incubators can provide access to market networks that would otherwise be out of reach for such companies (Scilitoe \& Chakrabarti, 2010). Networks help start-ups to gain new business contacts such as customers and suppliers, as well as access to new financial sources. For example, locating a start-up in an incubator can lead to increased credibility for the firm, which in turn reduces search costs for the firm and hence reduces the overall costs of transaction (Bruneel et al., 2012). This could be of particular relevance when firms are located in institutional settings in which business contacts still require the personal introduction in order to establish a certain amount of trust between the business parties (North, 1990). Personal business contacts are also important in countries in which law enforcement is seen as slow and costly (Bowen \& De Clercq, 2008; De Clercq et al., 2011; Estrin et al., 2013; La Porta, Lopez-de-Silanes, Shleifer \& Vishny, 1998). Vanderstraeten and Matthyssens (2012) found evidence that an extensive business network is a differentiating feature among the incubators in their study, opening the possibility for incubators to differentiate themselves from competition in the incubator market. Contrary to that, Chan and Lau (2005) found no indication for the use of networks provided by the science park for business start-ups in Hong Kong. The authors argue that the western-model of clustering might not be as successful in an eastern context.

For young start-ups, it is seen as difficult to establish a business network regardless of their location (GEM, 2012). However, the extent to which external network support is being accepted by tenants is expected to lead to variations between countries (Estrin et al., 2013). In particular related to finance, suppliers and buyers, as well as specialist know-how. Hence, the following hypothesis will be tested.

H4: Network services demands for entrepreneurs will vary across countries. 
The hypothesis proposed for testing defines the UBI environment in terms of four major factors derived from the current literature - goals/strategy, infrastructure, business support services, and networks. These are common factors across incubators around the world (Akcomak, 2009). This makes them fundamental in providing insights into UBI models across countries. The current article therefore suggests that testing of those can provide a measure for the extent to which the demand for UBI features vary between countries based on their differing institutional settings.

\section{MATERIAL AND METHODS}

Given the number of studies that have been conducted on universities incubators using qualitative research designs (Barbero et al., 2012; Bruneel et al., 2012; Chan \& Lau, 2005) it is argued here that a carefully crafted quantitative design is the most appropriate approach to provide indicative support for our study. This research employs a questionnaire survey in order to fulfil its research objective i.e. identifying demands from potential entrepreneurs for UBI features. This study is looking at two rather under researched countries that is the UAE and Thailand. The proposed quantitative survey method can provide expansive understanding of the focused topic however this method may lack indepth understanding as commonly found in the interview method. This article incorporates both undergraduate and graduate students in the survey in order to analyse the demand for university business incubator from two different backgrounds, with and without work-experience.

This study utilises survey data collected from undergraduate and postgraduate students in the UAE and Thailand. The students at each university had chosen an entrepreneurship or business planning module either at the undergraduate or MBA level. Due to their modules and/or experience they were already aware of the concept of UBI's, although none of the universities in the sample had a formal university business incubator established at that point.

The use of student surveys is not without criticism in the entrepreneurship literature (Robinson, Huefner \& Hunt, 1991). However, the approach has been proven valuable in several related studies in recent entrepreneurship literature (e.g. Fitzsimmons \& Douglas, 2011; Shepherd \& De Tienne, 2005). For this study it is also seen as a suitable approach for the following reasons. Firstly, the majority of cross-country studies uses institutional managers in their samples (Lee \& Osteryoung, 2004), which provide valuable insights, but do not directly address demand related issues. Secondly, in countries in which UBI's are still in their infancy or not existing at all, potential entrepreneurs are seen as providing valuable insights. Thirdly, university students are generally perceived as the major source for tenants at UBI's (Todorovic \& Suntornpithug, 2008). That implies that entrepreneurship students would be most likely the first group to be aware of such incubators and most likely the first tenants in newly founded UBI's. Lastly, mature and students that are far progressed in their studies stand at a point of career choice, of which becoming an entrepreneur is one feasible option (Shepherd \& De Tienne, 2005).

The measures for this survey have been adapted from the literature in order to increase reliability and validity of the scales. Special care has been taken in order to establish cross country data equivalence (Hult et al., 2008). Data collection equivalence has been accounted for in a way that all questionnaires were given out in the classroom and 
hence provide a similar setting for all participants. Construct equivalence has been established through pre-tests in each country. Measurement equivalence has been ensured through the use of consistent 7-point Likert scales, which have been identified as most appropriate for cross-country research (Harzing et al., 2009). Scale validity has been ensured through using scales based on previous studies and a pilot test with students and academics as well as discussion with a panel of experienced researchers. Scale reliability for each has been tested through Cronbach alphas tests that were all above the 0.7 threshold.

The questionnaire has been split into two main sections. Section A, following Fitzsimmons and Douglas (2011), asks for general information such as age, education, gender, and working experience.

Section B contained four subsections. The measures have been adapted from the relevant literature. Participants have been asked to rate the importance of 4 categories on a scale from 1 (not important) to 7 (very important) on goal and strategy i.e. 'What are the most important factors for you concerning the goals and strategy of the university business incubator?' (Lee \& Osteryoung, 2004; Vanderstraeten \& Matthyssens, 2012). For incubator infrastructure the respondents have been asked to rate 10 categories: 'What are the most important factors for you concerning the Infrastructure provided by the university business incubator?' (Bruneel et al., 2012; Ratinho, Harms \& Groen, 2013; Zabloki, 2007). Nine categories have been included for networks i.e. 'What are the most important factors for you concerning the networking services provided by the university business incubator?' (Bruneel et al., 2012; Chan \& Lau, 2005; Ratinho et al., 2013). For business support services the respondents have been asked to rate eight categories: 'How likely are you to use the following business support services provided by the university business incubator?' The categories can be found in table 2 in the next chapter. And the sample characteristics can be found in table 1 below.

Table 1. Sample characteristics

\begin{tabular}{|l|c|c|}
\hline \multicolumn{1}{|c|}{ Line item } & UAE & Thailand \\
\hline Sample size & 114 & 100 \\
\hline Gender & $51.8 \%$ male & $60.2 \%$ female \\
\hline Age & 25.3 years & 24.4 years \\
\hline Program enrolled & $78.1 \%$ Undergraduate & $53 \%$ Undergraduate \\
\hline Entrepreneurial experience & $74.6 \%$ no & $82 \%$ no \\
\hline Working experience & $71.1 \%$ yes & $53 \%$ no \\
\hline
\end{tabular}

Source: own calculation based on the research survey.

\section{RESULTS AND DISCUSSION}

The results of the analysis are provided in table 2 below. It provides the descriptive statistics (i.e. mean and standard deviation) for the total sample, the UAE and Thailand. In the first column of Table 2 we show the total mean. That is the result of all the respondents combined, i.e. Thailand and UAE. This column is provided in order to give an overview of the perception of all respondents concerning the issues that were being investigated. In order to test for the hypothesised differences, One-way ANOVA has been conducted. The significant F-Values are presented in the last column. The analysis follows 
previous studies such as Lee and Osteryoung (2004) for example. Concerning the discussion on ordinal versus interval scale, this article follows Labovitz (1970). Labovitz (1970)

Table 2. Descriptive statistics and ANOVA results

\begin{tabular}{|c|c|c|c|c|c|c|c|}
\hline \multirow[b]{2}{*}{ Category } & \multicolumn{2}{|c|}{ Total $(n=214)$} & \multicolumn{2}{|c|}{ UAE $(n=114)$} & \multicolumn{2}{|c|}{ Thailand $(n=100)$} & \multirow{2}{*}{$\frac{\text { ANOVA }}{\text { F value }}$} \\
\hline & Mean & $\begin{array}{l}\text { Std. } \\
\text { Dev. }\end{array}$ & Mean & $\begin{array}{l}\text { Std. } \\
\text { Dev. }\end{array}$ & Mean & Std. Dev. & \\
\hline \multicolumn{8}{|c|}{ Goals and Strategy } \\
\hline Broad business focus & 4.76 & 1.37 & 4.77 & 1.43 & 4.75 & 1.29 & \\
\hline Broad industry focus & 4.76 & 1.29 & 4.74 & 1.36 & 4.79 & 1.21 & \\
\hline Narrow industry focus & 4.69 & 1.31 & 4.70 & 1.42 & 4.67 & 1.19 & \\
\hline Narrow business focus & 3.82 & 1.49 & 3.67 & 1.39 & 4.00 & 1.59 & $2.69+$ \\
\hline \multicolumn{8}{|c|}{ Infrastructure } \\
\hline INF print and copy & 5.38 & 1.42 & 5.16 & 1.54 & 5.63 & 1.23 & $6.04^{*}$ \\
\hline INF parking & 5.13 & 1.54 & 5.13 & 1.44 & 5.13 & 1.66 & \\
\hline INF meeting rooms & 5.11 & 1.35 & 4.82 & 1.32 & 5.43 & 1.33 & $11.16 * *$ \\
\hline INF conference rooms & 4.99 & 1.31 & 4.73 & 1.34 & 5.29 & 1.23 & $10.16^{* *}$ \\
\hline INF reception services & 4.87 & 1.48 & 5.17 & 1.44 & 4.54 & 1.46 & $9.97 *$ \\
\hline INF production facilities & 4.78 & 1.46 & 4.88 & 1.45 & 4.67 & 1.48 & \\
\hline INF laboratories & 4.75 & 1.42 & 4.76 & 1.44 & 4.74 & 1.40 & \\
\hline INF individual office space & 4.64 & 1.46 & 4.67 & 1.48 & 4.60 & 1.44 & \\
\hline INF postal service & 4.64 & 1.55 & 4.96 & 1.45 & 4.28 & 1.60 & $10.56^{* *}$ \\
\hline INF shared office space & 4.37 & 1.32 & 4.04 & 1.29 & 4.74 & 1.26 & $15.82^{* * *}$ \\
\hline \multicolumn{8}{|c|}{ Business Support Services } \\
\hline BSSbusplan & 5.09 & 1.38 & 5.05 & 1.36 & 5.14 & 1.41 & \\
\hline BSSfaculty & 4.83 & 1.39 & 4.78 & 1.28 & 4.89 & 1.52 & \\
\hline BSSlaw & 4.83 & 1.50 & 4.82 & 1.51 & 4.84 & 1.48 & \\
\hline BSShr & 4.81 & 1.40 & 4.87 & 1.49 & 4.75 & 1.30 & \\
\hline BSSworkshops & 4.79 & 1.42 & 4.78 & 1.41 & 4.80 & 1.44 & \\
\hline BSSmentor & 4.79 & 1.30 & 4.76 & 1.31 & 4.83 & 1.29 & \\
\hline $\begin{array}{l}\text { BSS International Business } \\
\text { focus }\end{array}$ & 4.74 & 1.45 & 4.69 & 1.46 & 4.80 & 1.44 & \\
\hline BSScoaching & 4.72 & 1.41 & 4.76 & 1.36 & 4.68 & 1.48 & \\
\hline \multicolumn{8}{|c|}{ Networking Services } \\
\hline Financial institutions & 5.41 & 1.20 & 5.25 & 1.34 & 5.60 & 0.99 & $4.74 *$ \\
\hline Suppliers & 5.25 & 1.36 & 4.98 & 1.51 & 5.56 & 1.10 & $10.00^{*}$ \\
\hline Other tenants & 5.24 & 1.28 & 4.96 & 1.33 & 5.56 & 1.14 & $12.17^{* *}$ \\
\hline External consultants & 5.22 & 1.26 & 5.09 & 1.30 & 5.38 & 1.20 & $2.88+$ \\
\hline Business angels and VC & 5.21 & 1.31 & 5.10 & 1.36 & 5.34 & 1.23 & \\
\hline Other entrepreneurs & 5.20 & 1.34 & 4.96 & 1.41 & 5.47 & 1.20 & $7.81^{*}$ \\
\hline Accountants, legal experts, etc. & 5.15 & 1.27 & 5.18 & 1.33 & 5.12 & 1.21 & \\
\hline Business plan competitions & 5.10 & 1.28 & 4.96 & 1.32 & 5.27 & 1.22 & $3.23+$ \\
\hline Governmental institutions & 5.10 & 1.36 & 5.12 & 1.47 & 5.07 & 1.23 & \\
\hline
\end{tabular}

***p $<0.001,{ }^{* *} p<0.01,{ }^{*} p<0.05,+p<0.1$

Source: own elaboration.

conducts a Monte Carlo simulation in order to investigate potential measurement differences through assigning ordinal data to interval scales. The findings show that the differences are negligible, and do not outweigh the advantages gained from treating ordinal 
scales as interval. This notion is also shared by Nunnally and Bernstein (1994). Therefore, this study treats the scales as interval in the subsequent analysis.

In hypothesis 1 we expected a significant difference in the means between the two groups concerning the strategy and goals of the UBI. The results, however, show little difference between the respondents from Thailand and the UAE. Only one out of four items reaches statistical significance. The item indicates a slight preference among the Thai respondents for a more narrow business focus than the UAE sample. The total means of the construct hint towards a preference for a broader scope of businesses and industry sectors to be located in the UBI. This is nevertheless in line with our expectations, given that the incubator model is still a rather novel establishment in both countries. Potential entrepreneurs might therefore feel that a broader strategy adds more value for them than a too narrow focus. This finding links in the current debate on incubator strategy and goals. This study adds to this debate by providing some evidence for a distinct developing country perspective. It seems that reasons for a narrow strategic scope of the incubator as found by Vanderstraeten and Matthyssens (2012) might be less pronounced in the context of the UAE and Thailand. The authors suggest that specialised reputation of the incubator is an important factor for tenants to gain legitimacy in the market place. In the context of the current study, however, other factors might be more important. For example, having access to a wide range of knowledge sources might be perceived as more important than having a more industrial homogenous set of start-ups in the incubator. Furthermore, complex technology might make the need to have specialised firms more prominent, this seems to be the general message from the incubator and technology transfer literature (Rothaermel et al., 2007). However, for the UAE as well as Thailand is the development of complex technologies still in their infancy. Therefore is the need for technological specialisation of the incubator less evident.

Hypothesis 2 suggested that the basic infrastructure, or tangible services, provided by the UBI are of equal importance across countries, in line with findings in recent literature (Bruneel et al., 2012). However, significant differences in means between potential entrepreneurs in the UAE and Thailand have been found in six out of ten items. Respondents in Thailand valued print and copy facilities, meeting rooms, conference rooms, and shared office space higher than their UAE counterparts. On the other hand, reception services and postal services were higher valued by UAE based potential entrepreneurs. This might indicate the UBI's in the UAE might have to provide their tenants with more supporting service staff than UBI's in Thailand. This finding, the higher preference for shared service in UAE may reflect on a huge difference in labour cost between UAE and Thailand. The average minimal wage in Thailand is approximately USD 300 per month, five times smaller than USD 1,500 per month in UAE. Looking at the total descriptive statistics for the Infrastructure construct, it can be observed that shared office space has been valued the lowest by all respondents in the sample. This might indicate that there is little will by the respondents to follow western style design of incubators in which the sharing of ideas is one of the core principles (Chan \& Lau, 2005; Estrin et al., 2013).

In our third hypothesis we expected no significant differences in the demand for business support services between countries. The respondents from Thailand and the UAE confirmed this expectation, none of the F-values has been found significant. This is 
in line with the broader entrepreneurship literature in a way that it confirms a relatively homogenous demand across entrepreneurs in different countries for training and other human capital related activities (Bowen \& De Clercq, 2008; De Clercq et al., 2011; Estrin et al., 2013). Most notably in this case, the support for business plan development seems to have been most pronounced throughout the sample. The possibility to have access to specialist faculty within the university and business law consulting also scored high. Pointing towards a likely use of internal services provided by the incubator, which might be contrary to the findings of Ratinho et al. (2013) who found that tenants are less likely to use internal services as compared to external ones. However, their sample was based on incubators across Western Europe. In less developed institutional settings; however, the trust in external actors might be more limited (Bowen \& De Clercq, 2008; De Clercq et al., 2011; Estrin et al., 2013).

The last hypothesis suggested a significant difference between countries when it comes to the provision of networking services in UBI's. This was based on stark differences between the networking concepts in the west and non-western cultures (Estrin et al., 2013). This has been largely confirmed in this article. Six out of nine items showed significant $F$ values. This finding is in line with the qualitative observations made by Chan and Lau (2005) who indicated that the business incubator networking concept is only applicable to an East Asian context in a limited way. The findings of the present study seem to support their observation. In our sample, the Thai respondents seemed to be more inclined towards networking activities than the UAE ones. The most important items were networking activities with financial institutions, followed by suppliers. On third rank from the total scores we find contacts with other tenants. This might indicate that pragmatic networking activities are given priority over the more innovation focussed networking activities with fellow tenants or other entrepreneurs. For this particular sample, the respondents from Thailand had higher scores in all but two items compared to the UAE respondents. Accountants and legal experts as well as networking activities linking to governmental institutions were more important for UAE potential entrepreneurs; however, the difference was not statistically significant. Contact with suppliers, other tenants, and other entrepreneurs where significantly more important for the respondents in Thailand.

\section{CONCLUSIONS}

This research set out with the objective to shed further light on the demand side of UBI service provision. UBI's can create important platforms for the nurturing of new business ventures in their early stages, especially in less technology driven developing countries (Lalkaka, 2002). It aimed at highlighting differences between potential entrepreneurs and their demands on services provided by UBI's that follow the North American 'blueprint'. For this purpose, an institutions-based framework has been suggested. The subsequent indicative survey has been conducted with potential entrepreneurs in the UAE and Thailand.

The results indicate that there are significant differences between the two countries and their service provision requirements for UBI's. Overall, a broader scope for incubators goals and strategies seems to be preferred. This might be because of the lagging 
technological complexity of industries in both countries. Broader business sector orientation might be more successful for the attraction of tenants in developing countries.

Differences have also been identified regarding the importance of infrastructure provision by incubators. More service based demands have been made by the UAE respondents, whereas the tangible side e.g. copy facilities or meeting rooms have been found more important in the Thailand sample. Overall, shared office space seemed to have a rather low standing in both countries, which also hints towards limitations of the networking and idea exchange concepts originating from the western literature and developed under different perceptions of trust (Baumol, 1990; North, 1990).

There were no differences between the two countries concerning the provision of business support services. Support in business plan development has been ranked highest by all respondents. This was in line with recent entrepreneurship literature, which emphasise the importance of human capital development in business start-ups. (Bowen \& De Clercq, 2008; De Clercq et al., 2011; Estrin et al., 2013).

Significant differences have been found for networking service items. A more pragmatic tendency seems to drive the importance of the items. Contacts with other entrepreneurs outside the incubator, as well as other tenants inside the incubator have been given less importance than contacts with suppliers and financial institutions.

This research has two main managerial implications. Firstly, given the focus of this study on two developing economies, the demand indicators showed that a preference is given to broader strategic outlook of UBI's. That is because the incubator concept might not be as common in those countries as it is in the US or UK for example. Universities might therefore be advised to provide their reputational effects to a broader spectrum of tenants from various industries. Secondly, in order to establish a successful incubator, it might be preferable to follow local demands, rather than the North American blueprint. Important is also to take the local requirements into account when it comes to the provision of infrastructure as well as networking services. This plays also a role for policy makers.

The policy implications of this research are certainly to pay attention that universities follow local demands rather than establishing state of the art incubators that will end up being underutilised and hence abandoned. In particular, non-technology based incubators could be a successful concept for developing countries to nurture business start-ups in their early phase, provided those are aligned to the formal and informal institutional setting of the country.

There are several limitations of this study that should be overcome in future studies. The sample was based on university students from two different universities. Further studies could expand the sample size in order to increase representativeness. Continuing research is required outside the mainstream regions in order to develop a more complete picture of UBI's success and failure in developing countries. For instance, future studies can be conducted on UBI in African and South American countries. In addition, more comparative studies should be carried out within such a context in order to establish stronger patterns of localisation of incubator concepts and hence establish benchmarks if not globally, but at least on a regional level. 


\section{REFERENCES}

Akçomak, I.S. (2009). Incubators as tools for Entrepreneurship Promotion in Developing countries (No. 2009.52). Research paper/UNU-WIDER.

Aerts, K., Matthyssens, P., \& Vandenbempt, K. (2007). Critical role and screening practices of European business incubators. Technovation, 27(5), 254-267.

Barbero, J.L., Casillas, J.C., Ramos, A., \& Guitar, S. (2012). Revisiting incubation performance: How incubator typology affects results. Technological Forecasting and Social Change, 79(5), 888902.

Baumol, W.J. (1990). Entrepreneurship: Productive, unproductive and destructive. Journal of Political Economy, 98(5), 893-921.

Bowen, H.P., \& De Clercq, D. (2008). Institutional context and the allocation of entrepreneurial effort. Journal of International Business Studies, 39(4), 747-767.

Bruneel, J., Ratinho, T., Clarysse, B., \& Groen, A. (2012). The Evolution of Business Incubators: Comparing demand and supply of business incubation services across different incubator generations. Technovation, 32(2), 110-121.

Chan, K.F., \& Lau, T., (2005). Assessing technology incubator programs in the science park: the good, the bad and the ugly. Technovation, 25(10), 1215-1228.

De Clercq, D., Lim, D.S., \& Oh, C.H. (2011). Individual-Level Resources and New Business Activity: The Contingent Role of Institutional Context. Entrepreneurship Theory and Practice, 37(2), 303-330.

Estrin, S., Korosteleva, J., \& Mickiewicz, T. (2013). Which institutions encourage entrepreneurial growth aspirations?. Journal of business venturing, 28(4), 564-580.

EC (2002). Benchmarking of business incubators. Brussels: European Commission.

Fitzsimmons, J.R., \& Douglas E.J. (2011). Interaction between feasibility and desirability in the formation of entrepreneurial intentions. Journal of Business Venturing, 26(4), 431-440.

Friedrich, F., Harley, B., \& Langbein, J. (2010). Development guidelines for technology business incubators. Bonn: InWEnt - Internationale Weiterbildung und Entwicklung gGmbH.

GEM (2012). The global entrepreneurship monitor. Retrieved on 10 April, 2016 from www.gemconsortium.org/docs/ download,2409

GEM (2011). Entrepreneurship in the United Arab Emirates. Retrieved on 10 April, 2016 from www.gemconsortium. org/docs/download,2409

GEM Thailand (2012). Thailand Report. Retrieved on 10 April, 2016 from www.gemconsortium.org/docs/download, 2409

Grimaldi, R., \& Grandi, A. (2005). Business incubators and new venture creation: an assessment of incubating models. Technovation, 25(2), 111-121.

Guerrero, M., Urbano, D., \& Salamzadeh, A. (2015). Entrepreneurial transformation in the Middle East: experiences from Tehran Universities. Technics Technologies Education Management, 10(4), 533-537.

Harzing, A.W., Baldueza, J., Barner-Rasmussen, W., Barzantny, C., Canabal, A., Davila, A. et al. (2009). Rating versus ranking: What is the best way to reduce response and language bias in cross-national research? International Business Review, 18(4), 417-432.

Hult, G.T., Ketchen, D.J., Griffith, D.A., Finnegan, C.A., Gonzalez-Padron, T., Harmancioglu, N., Huang, Y., Talay, M.B., \& Cavusgil, S.T. (2008). Data equivalence in cross-cultural international 
business research: assessment and guidelines. Journal of International Business Studies, 39(6), 1027-1044.

Labovitz, S. (1970). The Assignment of Numbers to Rank Order Categories. American Sociological Review, 35(3), 515-524.

Lalkaka, R. (2002). Technology business incubators to help build an innovation-based economy. Journal of Change Management, 3(2), 167-176.

Lalkaka, R. (2003). Business incubators in developing countries: characteristics and performance. International Journal of Entrepreneurship and Innovation Management, 3(1-2), 31-55.

La Porta, R., Lopez-de-Silanes, F., Shleifer, A., \& Vishny, R.W. (1998). Law and Finance. Journal of Political Economy, 106(6), 1113-1155.

Lee, S.S., \& Osteryoung, J.S. (2004). A comparison of critical success factors for effective operations of university business incubators in the United States and Korea. Journal of Small Business Management, 42(4), 418-426.

Mian, S.A. (1996). Assessing value added contributions of university technology business incubators to tenant firms. Research Policy, 25(3), 325-335.

North, D.C. (1990). Institutions, institutional change and economic performance. Cambridge: Cambridge University Press.

Nunnally, J.C., \& Bernstein, I.H. (1994). Psychometric theory. London: McGraw-Hill.

Ratinho, T., Harms, R., \& Groen, A. (2013). Business Incubators: (How) Do They Help Their Tenants? New Technology-Based Firms in the New Millennium, 10, 161-182.

Robinson, P.B., Huefner, J.C., \& Hunt, K.H. (1991). Entrepreneurial research on student subjects does not generalize to real world entrepreneurs. Journal of Small Business Management, 29(2), 42-50.

Rothaermel, F.T., Agung, S.D., \& Jiang, L. (2007). University entrepreneurship: a taxonomy of the literature. Industrial and corporate change, 16(4), 691-791.

Scaramuzzi, E. (2002). Incubators in developing countries: Status and development perspectives. Washington DC: The World Bank.

Schwartz, M., \& Hornych, C. (2010). Cooperation patterns of incubator firms and the impact of incubator specialization: Empirical evidence from Germany. Technovation, 30(9), 485-495.

Scillitoe, J.L., \& Chakrabarti, A.K. (2010). The role of incubator interactions in assisting new ventures. Technovation, 30(3), 155-167.

Shepherd, D., \& DeTienne, D. (2005). Prior Knowledge, Potential Financial Reward, and Opportunity Identification. Entrepreneurship Theory and Practise, 29(1), 91-112.

Todorovic, Z.W., \& Suntornpithug, N. (2008). The multi-dimensional nature of university incubators: capability/resource emphasis phases. Journal of Enterprising Culture, 16(4), 385-410.

Tsai, F.S., Hsieh, L.H., Fang, S.C., \& Lin, J.L. (2009). The co-evolution of business incubation and national innovation systems in Taiwan. Technological Forecasting and Social Change, 76(5), 629-643.

Vanderstraeten, J., \& Matthyssens, P. (2012). Service-based differentiation strategies for business incubators: Exploring external and internal alignment. Technovation, 32(12), 656-670.

Zablocki, E.M. (2007). Formation of a Business Incubator. In A. Krattiger, R.T. Mahoney, L. Nelsen, J.A. Thomson, A.B. Bennett, \& S.P. Kowalski (Eds.), Intellectual Property Management in Health and Agricultural Innovation: A Handbook of Best Practices (pp. 1305-1314). Oxford, UK: MIHR and Davis, USA: PIPRA. 


\section{Author}

The contribution of co-authors is equal and can be expressed as $50 \%$ each of the authors: S. Dahms developed the concept and collected data. S. Kingkaew collected data, reviewed paper, presented at conference and revised paper after receiving review.

\section{Sven Dahms}

Assistant Professor (I-Shou University, International Business Administration, Kaohsiung Taiwan), PhD in Management (Manchester Metropolitan University, UK), Degree in Economics from University of Hagen.

Correspondence to: Sven Dahms; I-Shou University, International Business Administration, Kaohsiung Taiwan; 1 Syuecheng Rd., Dashu District, Kaohsiung City 84001,Taiwan, R.O.C.; e-mail: svendahms@hotmail.com

\section{Suthikorn Kingkaew}

Lecturer in International Business (Thammasat Business School, Thammasat University, Thailand), PhD in Management Studies and Master of Philosophy in Technology Policy (Cambridge Judge Business School, Cambridge University, UK), Bachelor in Biotechnology (University of New South Wales, Australia).

Correspondence to: Suthikorn Kingkaew; Thammasat Business School, Thammasat University; 2 Prachan Road, Pranakorn, Bangkok 10200, Thailand; e-mail: suthikorn@tbs.tu.ac.th

\section{Acknowledgements and Financial Disclosure}

The authors would like to thank the anonymous reviewers for their useful comments, which allowed increasing the value of this article.

\section{Copyright and License}

This article is published under the terms of the Creative Commons Attribution - NonCommercial - NoDerivs (CC BY-NC-ND 3.0) License http://creativecommons.org/licenses/by-nc-nd/3.0/ 